\title{
Strategy for Controlling the Properties of Bioactive Poly-Ether- Ether-Ketone/Hydroxyapatite Composites for Bone Tissue Engineering Scaffolds
}

\author{
Gaoyan Zhong, ${ }^{*},+,, \S, \# \odot$ Mohammad Vaezi, ${ }^{\ddagger} \|, \perp, \#$ Xinliang Mei, ${ }^{\dagger}$ Ping Liu, ${ }^{\dagger}$ and Shoufeng Yang ${ }^{*}, \dagger, \ddagger$ \\ ${ }^{\dagger}$ College of Engineering, Nanjing Agricultural University, Nanjing 210031, Jiangsu, China \\ ${ }^{\ddagger}$ Faculty of Engineering and the Environment, University of Southampton, Southampton SO17 1BJ, Hampshire, U.K. \\ ${ }^{\S}$ State Key Laboratory of Materials Processing and Die \& Mould Technology, Huazhong University of Science and Technology, \\ Wuhan 430074, Hubei, China \\ "Department of Mechanical Engineering and Marine Technology, University of Rostock, Rostock 18059, Germany \\ ${ }^{\perp}$ Department of Mechanical Engineering, Babol Noshirvani University of Technology, Babol 4714871167, Mazandaran, Iran
}

Supporting Information

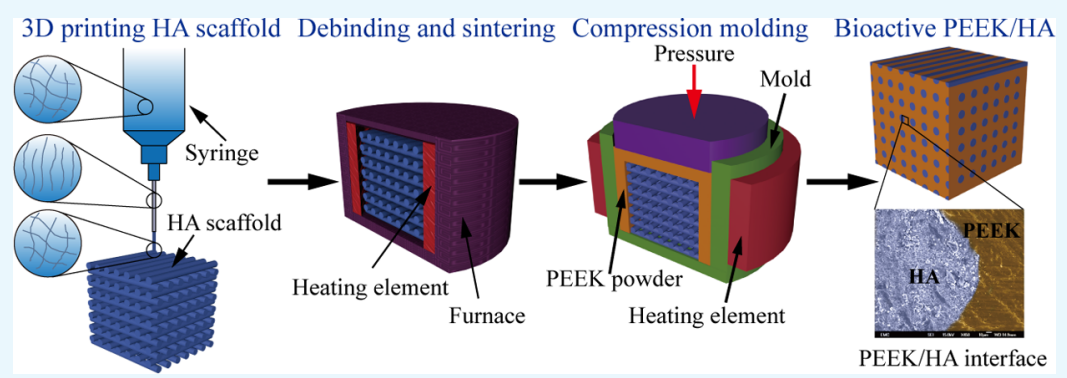

ABSTRACT: A strategy for the preparation of bioactive poly-ether-ether-ketone/hydroxyapatite (PEEK/HA) composites was proposed in this study with the aim of controlling the biological and mechanical properties of different parts of the composites. The strategy integrated solvent-based extrusion freeforming 3D printing technology in order to print high-resolution HA scaffolds and compression molding processes for the production of bioactive PEEK/HA composites. To this end, an optimized model, established using response surface methodology, was employed to optimize the extrusion process parameters on the basis of accurate characterization of the extrusion pressure, and the effects of the filament/pore sizes on the PEEK infiltration depth into the HA scaffold were investigated. The results of scanning electron microscopy and computed tomography analyses revealed that the PEEK/HA composites exhibited a uniform microstructure and a good interface between the HA filaments and the PEEK matrix following the optimization of the process parameters. The HA scaffolds were fully infiltrated by PEEK in both vertical and lateral directions with an infiltration depth of $3 \mathrm{~mm}$ while maintaining the HA network structure and uniformity. The biological and mechanical performance test results validated that the PEEK/HA composites possessed excellent biocompatibility as well as yields and compressive strengths within the range of human cortical bone suitable for load-bearing applications.

\section{INTRODUCTION}

A strong demand will continue to grow for bone injury repair or replacement owing to an increase in the aging population as well as industry, transport, sports, and other causes, because bone repair or replacement can improve the quality of life of thousands of patients. However, the defects of stress shielding or poor mechanical strength limit bone scaffolds, especially load-bearing bone scaffolds, to wider applications. ${ }^{1-3}$ Polyether-ether-ketone (PEEK) is a high-performance, semicrystalline thermoplastic that is an excellent alternative for metal biomaterials because it has good biocompatibility with no cytotoxic effects in vivo. The elastic modulus of PEEK is similar to that of cortical bone, ${ }^{4-8}$ which has been used as a load-bearing orthopedic implant material with clinical applications in recent years. However, despite its widespread use in bone damage repair, a potential clinical concern is that PEEK is not bioactive enough and has limited fixation with bone, which means that smooth PEEK implants fabricated by conventional manufacturing methods can exhibit poor osseointegration and potentially result in clinical failure. ${ }^{3}$ Therefore, manufacturing PEEK-based implants is an extremely challenging task.

To improve the osseointegration of PEEK-based implants, three main strategies have been developed for different orthopedic applications: (1) the incorporation of bioactive materials such as calcium phosphates or hydroxyapatite (HA)

Received: August 11, 2019

Accepted: October 23, 2019 


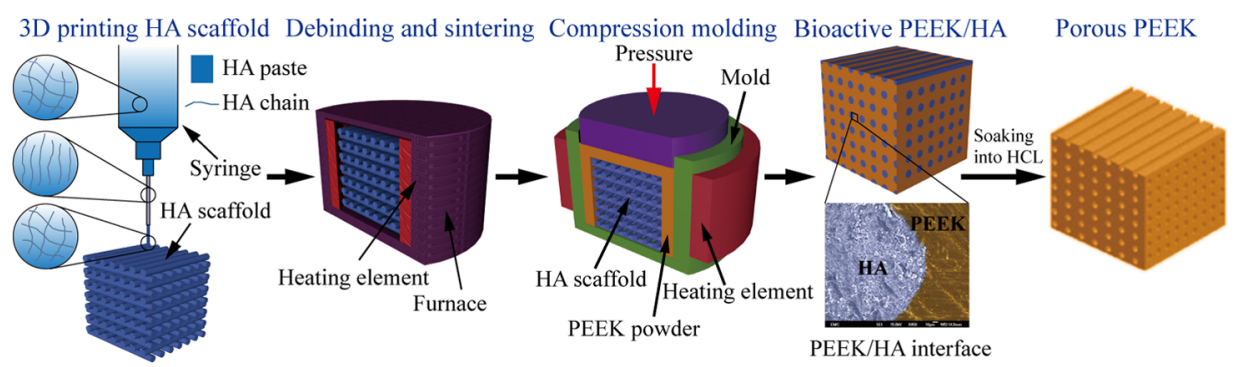

Figure 1. Preparation method of bioactive PEKK/HA composite and porous PEEK in our study.

Table 1. Materials Being Used to Form the PEEK/HA Composite in This Study

\begin{tabular}{|c|c|c|c|c|c|}
\hline No. & Material & Molecular formula & $\begin{array}{l}\text { Melting point } \\
\left({ }^{\circ} \mathrm{C}\right)\end{array}$ & $\begin{array}{l}\text { Density } \\
\left(\mathrm{g} / \mathrm{cm}^{3}\right)\end{array}$ & $\begin{array}{c}\text { particle size } \\
(\mu \mathrm{m})\end{array}$ \\
\hline 1 & HA (powder) & $\mathrm{Ca}_{10}\left(\mathrm{PO}_{4}\right)_{6}(\mathrm{OH})_{2}$ & 1650 & 3.156 & $1-5$ \\
\hline 2 & PVB (binder) & $\mathrm{C}_{14} \mathrm{H}_{18} \mathrm{ClN}_{3} \mathrm{~S}$ & Amorphous & 1.100 & - \\
\hline 3 & PEG (plasticizer) & $\mathrm{HO}\left(\mathrm{CH}_{2} \mathrm{CH}_{2} \mathrm{O}\right) \mathrm{nH}$ & $64-66$ & 1.127 & - \\
\hline 4 & propan-2-ol (solvent) & $\left(\mathrm{CH}_{3}\right)_{2} \mathrm{CHOH}$ & -88.5 & 0.789 & - \\
\hline 5 & PEEK (powder) & & 334 & 1.29 & 10 (Average) \\
\hline
\end{tabular}

into PEEK with the potential for osseointegration, ${ }^{9,10}$ (2) coating PEEK implants with biomaterials such as titanium or $\mathrm{HA}^{11-13}$ and (3) incorporating porosity into PEEK implants. $^{3,14,15}$ Of these three main strategies, the addition of bioactive materials along with the incorporation of porosity into PEEK has been identified as an effective approach for improving bone-implant interfaces and for the osseointegration of PEEK-based devices. ${ }^{1}$ Many manufacturing methods such as compounding and injection molding and cold press sintering have been used to produce bioactive PEEK/HA composites. $^{16-18} \mathrm{~A}$ number of researchers have reported that the addition of bioactive phase materials and the incorporation of porosity into PEEK are effective approaches for improving the bone-implant interfaces and for the osseointegration of PEEK-based implants. ${ }^{1-3,9,10,14,15,19-26}$ However, the conventional addition method often mixes bioactive materials with PEEK. For example, Yuan and co-authors hand mixed HA microspheres and PEEK powder and then prepared PEEK/HA composite samples under heat and pressure. Porous PEEK samples were prepared after soaking PEEK/HA composites in an $\mathrm{HCl}$ solution to remove the $\mathrm{HA}$ microspheres. ${ }^{20,21}$ In this way, it signifies that the size and location of the pores in porous PEEK are uncontrollable, which means that the biological and mechanical properties of PEEK-based implants cannot be controlled.

Among the many strategies developed to solve the above problems, Yang's research team proposed a novel approach for the production of bioactive PEEK/HA bone scaffolds with a unique configuration in which the bioactive material HA distribution is computer-controlled within a PEEK matrix. ${ }^{22-26}$ In this manner, the biological and mechanical properties of different parts of the bone scaffolds can be controlled macroscopically. This novel approach has low cost, and there is no theoretical limit to the proportion of bioactive materials added. However, the crux of the preparation of bioactive $\mathrm{PEEK} / \mathrm{HA}$ bone scaffolds with the required performance is the accurate control of the process parameters such as the accurate characterization of the extrusion pressure and optimizing both the $3 \mathrm{D}$ printer system and its printing parameters. Poor control of the process parameters would result in a failure of the bone scaffold preparations because bone scaffolds must have a highly controlled 3D macrostructure and microstructure to accurately mimic the native tissue environment. A scaffold may have simple or complicated macrostructures depending on the application, but its microstructure is the factor that affects the regeneration of specific tissues using synthetic substances. ${ }^{26}$ In addition, there must be a good bonding interface between the HA filaments and the PEEK matrix in order to improve the osseointegration ability of PEEK-based bone scaffolds.

In this study, a strategy for the preparation of bioactive PEEK/HA composites was investigated by optimizing the process parameters in order to accurately control the properties of bioactive PEEK/HA composites on the basis of our previous research. ${ }^{26}$ For this purpose, an optimized model established using response surface methodology (RSM) based on Box-Behnken design (BBD) was employed to optimize the extrusion process parameters on the basis of accurate characterization of the extrusion pressure. The effects of the filament/pore sizes on the PEEK infiltration depth into the HA scaffold were investigated. After that, the microstructures and the bonding interface between HA and PEEK were analyzed by scanning electron microscopy (SEM) and computed tomography (CT) techniques, and the biological and mechanical properties of the composites were tested. This study aims to present results that can serve as a guide for the preparation of bioactive PEEK/HA composites suitable for bone tissue engineering scaffold applications by accurately controlling the properties of bioactive PEEK/HA composites.

\section{MATERIALS AND METHODS}

2.1. Fabricating Method. The method used to fabricate bioactive PEEK/HA composites with controlled biological and mechanical properties is presented in Figure 1. Porous bioactive HA scaffolds were first fabricated using solventbased extrusion freeforming (SEF) 3D printing technology, after which PEEK melt was infiltrated into the HA scaffolds using the compression molding process. The biological and mechanical properties could be tailored by varying the 
percentage of bioactive HA materials (such as by varying the HA filament and/or pore sizes). The detailed fabricating method is presented in Table S1.

In contrast to the method shown in refs 20 and 21, the method illustrated in Figure 1 can control the biological and mechanical properties of different parts of PEEK/HA composites because the HA filament and/or pore sizes can be arbitrarily controlled using SEF 3D printing technology according to different applications. For example, the use of HA scaffold with computer-controlled varied spacing can make functionally graded PEEK/HA composites for spinal cage fusion, $^{22,25}$ and the distribution of bioactive phase materials HA by computer-control in these composites also ensured uniform distribution of the load onto the device after implantation.

2.2. Fabricating Materials. The following materials were used to form a PEEK/HA composite in this study: (1) HA powder (Grade P221 S, Plasma Biotal Ltd. UK), (2) adhesive binder polyvinyl butyral (Grade BN18, Whacker Chemicals, UK), (3) plasticizer polyethyleneglycol (Whacker Chemicals, UK), (4) propan-2-ol (Fisher Scientific, UK), and (5) PEEK OPTIMA LT3 UF (Invibio Biomaterials Solutions, UK), as shown in Table 1. Of these, materials (1)-(4) were used to form the ceramic pastes for the $3 \mathrm{D}$ printing $\mathrm{HA}$ scaffold, and material (5) was used to produce a PEEK/HA composite through a compression molding process.

2.3. Optimization Method of Extrusion Process Parameters. From Figure 1, it can be observed that the successful printing of HA scaffold with SEF technology is very important for the preparation of bioactive PEEK/HA composite. In our previous research, ${ }^{26}$ a novel method, namely, the three-point experimental extrapolation, was executed to analyze the necessary extrusion pressure in relation to the extrusion velocity. On this basis, to find the optimal printing parameters and reduce the extrusion pressure as much as possible, an RSM based on BBD was employed to optimize the extrusion process parameters. An RSM is an effective mathematical and statistical tool based on the fit of a polynomial equation to the experimental data, which can be used to optimize multifaceted processes and evaluate the effects of multiple variables and their interactions. ${ }^{27,28}$ It has been successfully used to optimize multiple parameters in many areas, ${ }^{27-33}$ but the optimization of printing parameters in SEF technology for bone scaffolds has not been reported.

In this study, three selected independent printing parameter variables, that is, the paste formulation (solvent content), the nozzle length-to-diameter ratio $(L / D)$, and the extrusion velocity $(V)$ were chosen as the critical variables and, respectively, designated as $A, B$, and $C$, as tabulated in Table 2 . The levels of each variable were, respectively, designated as $-1,0$, and +1 . All experiments were carried out in a random order using different parameters, and the low and high levels of

Table 2. Experimental Range and Levels of Independent Variables

\begin{tabular}{|c|c|c|c|c|c|}
\hline \multirow[b]{2}{*}{ variables } & \multirow[b]{2}{*}{ symbol } & \multirow[b]{2}{*}{ unit } & \multicolumn{3}{|c|}{ range and levels (codes) } \\
\hline & & & $\begin{array}{c}-1 \\
\text { (low level) }\end{array}$ & $\begin{array}{c}0 \\
\text { (center level) }\end{array}$ & (high level) \\
\hline $\begin{array}{l}\text { solvent } \\
\text { content }\end{array}$ & $A$ & wt $\%$ & 10.2 & 12.7 & 15.2 \\
\hline$L / D$ & $B$ & & 32 & 79.5 & 127 \\
\hline velocity $(V)$ & C & $\mathrm{mm} / \mathrm{s}$ & 2.7 & 5.35 & 8.0 \\
\hline
\end{tabular}

the factors were selected according to our previous experiments. $^{26}$

The extrusion pressure was multiply regressed with respect to the different printing parameters using the least squares method, as follows ${ }^{28}$

$$
y=\beta_{0}+\sum_{i=1}^{k} \beta_{i} x_{i}+\sum_{i=1}^{k} \beta_{i i} x_{i}^{2}+\sum_{i=1}^{k-1} \sum_{j=i+1}^{k} \beta_{i j} x_{i} x_{j}+\varepsilon
$$

where $y$ is the response variable (here, it is the extrusion pressure $P$ ), $x_{i}$ and $x_{j}$ are the independent printing parameter variables (here, these are $A, B$, and $C$ ), $k$ is the number of tested variables (here, $k=3$ ), and $\varepsilon$ is the residual, which is used to adjust the regression accuracy. The regression coefficient is defined as $\beta_{0}$ for the intercept, $\beta_{i}$ for linear terms, $\beta_{i i}$ for quadratic terms, and $\beta_{i j}$ for crossproduct terms. Therefore, the regression model initially established in this study was as shown in eq 2 .

$$
\begin{aligned}
y= & \beta_{0}+\beta_{1} A+\beta_{2} B+\beta_{3} C+\beta_{12} A B+\beta_{13} A C+\beta_{23} B C \\
& +\beta_{11} A^{2}+\beta_{22} B^{2}+\beta_{33} C^{2}+\varepsilon
\end{aligned}
$$

An RSM experiment based on a BBD was used to optimize the extrusion process. Seventeen experiments were designed by Design-Expert 8.0 software for use in this study. The statistical testing of the regression equation was checked by F-test and the analysis of variance (ANOVA) for the fitted quadratic polynomial model of the extrusion pressure. The regression model established after optimization was as shown in eq 3 . The detailed analysis results will be discussed in the next section.

$$
\begin{aligned}
y= & \beta_{0}+\beta_{1} A+\beta_{2} B+\beta_{3} C+\beta_{12} A B+\beta_{23} B C+\beta_{22} B^{2} \\
& +\varepsilon
\end{aligned}
$$

2.4. Optimization of Compression Molding Parameters. SEM and CT techniques play an important role in microstructure analysis. ${ }^{34-39}$ In this study, a series of HA scaffolds with a range of filament and pore sizes were $3 \mathrm{D}$ printed and subsequently overmolded to investigate the effects of the filament/pore sizes on the PEEK infiltration depth into the HA scaffold. The samples were cut using a diamond cutter (Mecatome T210, Presi, France). The infiltration depth was measured with the use of optical microscopy (Olympus BH2UMA, Japan). SEM (JEOL JSM-6500F, Oxford Instruments) and CT (Custom $225 \mathrm{kV}$ Nikon/Metris HMX ST) were used for the analysis of the microstructures of the samples. The optimal temperature and pressure were determined through experimentation on overmolding $\mathrm{HA}$ scaffolds with external dimensions of $10 \times 10 \times 3 \mathrm{~mm}^{3}$.

\section{RESULTS AND DISCUSSION}

3.1. Checking the Fitted Models and the Statistical Analysis. ANOVA was performed for the fitted quadratic polynomial model eqs 2 and 3 before and after optimization of the extrusion pressure with the measured values given in Table 3. From Table 3, it can be observed that the models' F-values of 110.73 and 193.29 before and after optimization imply that the models were significant. There was only a $0.01 \%$ chance that a "model F-value" this large could occur due to noise. $P$ values less than 0.05 indicate that the model terms were significant. In this case $A, B, C, A B, B C$, and $B^{2}$ were significant model terms. Values greater than 0.1000 indicated that the model terms were not significant. Therefore, the insignificant 
Table 3. ANOVA for the Fitted Quadratic Polynomial Model before and after Optimization

\begin{tabular}{|c|c|c|c|c|c|c|c|c|c|c|}
\hline \multirow[b]{2}{*}{ source } & \multicolumn{5}{|c|}{ before optimization } & \multicolumn{5}{|c|}{ after optimization } \\
\hline & SS & $\mathrm{df}$ & MS & F-value & $P$-value & SS & df & MS & F-value & $P$-value \\
\hline model & 192.31 & 9 & 21.37 & 110.73 & $<0.0001$ & 192.00 & 6 & 32.00 & 193.29 & $<0.0001$ \\
\hline$A$ & 25.67 & 1 & 25.67 & 133.03 & $<0.0001$ & 25.67 & 1 & 25.67 & 155.04 & $<0.0001$ \\
\hline$B$ & 103.82 & 1 & 103.82 & 538.06 & $<0.0001$ & 103.82 & 1 & 103.82 & 627.12 & $<0.0001$ \\
\hline C & 43.01 & 1 & 43.01 & 222.91 & $<0.0001$ & 43.01 & 1 & 43.01 & 259.81 & $<0.0001$ \\
\hline$A B$ & 6.38 & 1 & 6.38 & 33.04 & 0.0007 & 6.38 & 1 & 6.38 & 38.51 & 0.0001 \\
\hline$A C$ & 0.06 & 1 & 0.06 & 0.32 & 0.5871 & & & & & \\
\hline$B C$ & 3.40 & 1 & 3.40 & 17.64 & 0.0040 & 3.40 & 1 & 3.40 & 20.56 & 0.0011 \\
\hline$A^{2}$ & 0.04 & 1 & 0.04 & 0.20 & 0.6706 & & & & & \\
\hline$B^{2}$ & 9.44 & 1 & 9.44 & 48.93 & 0.0002 & 9.72 & 1 & 9.72 & 58.69 & $<0.0001$ \\
\hline$C^{2}$ & 0.19 & 1 & 0.19 & 1.01 & 0.3487 & & & & & \\
\hline residual & 1.35 & 7 & 0.19 & & & 1.66 & 10 & 0.17 & & \\
\hline lack of fit & 1.35 & 3 & 0.45 & & & 1.66 & 6 & 0.28 & & \\
\hline pure error & 0.00 & 4 & 0.00 & & & 0.00 & 4 & 0.00 & & \\
\hline cor total & 193.66 & 16 & & & & 193.66 & 16 & & & \\
\hline$R^{2}$ & \multicolumn{5}{|c|}{0.9930} & \multicolumn{5}{|c|}{0.9915} \\
\hline adj. $R^{2}$ & \multicolumn{5}{|c|}{0.9841} & \multicolumn{5}{|c|}{0.9863} \\
\hline pred. $R^{2}$ & \multicolumn{5}{|c|}{0.8884} & \multicolumn{5}{|c|}{0.9613} \\
\hline adeq. precision & \multicolumn{5}{|c|}{35.151} & \multicolumn{5}{|c|}{45.357} \\
\hline
\end{tabular}

items were removed from the regression equation after optimization. Meanwhile, it is also observable that the pred. $R^{2}$ of 0.9613 was in reasonable agreement with the adj. $R^{2}$ of 0.9863 after optimization, which was better than that of before optimization. The adeq. precision term was used to measure the signal-to-noise ratio, for which a value greater than 4 was desirable. The ratio of 45.375 after optimization was greater than that of 35.151 before optimization. The final regression model before and after optimization is presented in eq 4 .

$$
\left\{\begin{array}{l}
\text { Before optimization: } \\
\begin{array}{rl}
P= & 10.93-1.79 A+3.60 B+2.32 C-1.26 A B \\
& +0.13 A C+0.92 B C-0.09 A^{2}-1.50 B^{2}-0.22 C^{2} \\
& +0.26
\end{array} \\
\text { After optimization: } \\
\begin{array}{rl}
P= & 10.79-1.79 A+3.60 B+2.32 C-1.26 A B \\
& +0.92 B C-1.51 B^{2}+0.11
\end{array}
\end{array}\right.
$$

where the values of $A, B$, and $C$ are calculated with codes of $-1,0$, and 1 , respectively.

Seventeen RSM experiments were inserted into equation set (4), and the data for the two models were compared with the measured values. The results of this comparison are presented in Table S2. The analysis results indicate that the model after optimization had an adequate signal that could be used to optimize the extrusion parameters.

3.2. Optimization of Extrusion Process Parameters. In order to ensure the stiffness of the $3 \mathrm{D}$ printing system, we developed a SEF 3D printer with the designed maximum extrusion pressure of $20 \mathrm{MPa}$ for the printing of highresolution scaffolds. ${ }^{26}$ According to the analysis of paste extrusion process, ${ }^{26}$ the target values of the control factors $A$, $B$, and $C$ were set to $10.2 \mathrm{wt} \%, 32$, and $8 \mathrm{~mm} / \mathrm{s}$, respectively. The purpose of this setting was to increase the extrusion efficiency and to make the paste extrude smoothly. Table 4 presents some of the optimization results.

From Table 4, it is observable that extrusion pressure after optimization was much lower than the designed maximum
Table 4. Some of the Optimization Results of the Extrusion Parameters with the RSM Based on a BBD

\begin{tabular}{lccccc} 
no & $\begin{array}{c}\text { solvent } \\
\text { content } \\
(\text { wt \%) }\end{array}$ & $L / D$ & $\begin{array}{c}\text { velocity } \\
(\mathrm{mm} / \mathrm{s})\end{array}$ & $\begin{array}{c}\text { extrusion } \\
\text { pressure }(\mathrm{MPa})\end{array}$ & $\begin{array}{c}\text { desirability } \\
(\%)\end{array}$ \\
\hline 1 & 10.20 & 32.00 & 8.00 & 7.60 & 99.99 \\
2 & 10.20 & 32.00 & 7.98 & 7.59 & 99.86 \\
3 & 10.22 & 32.00 & 8.00 & 7.59 & 99.84 \\
4 & 10.20 & 32.00 & 7.93 & 7.56 & 99.55 \\
5 & 10.20 & 32.00 & 7.88 & 7.54 & 99.27 \\
6 & 10.20 & 34.07 & 8.00 & 7.98 & 99.27 \\
7 & 10.20 & 34.40 & 8.00 & 8.04 & 99.15 \\
8 & 10.40 & 32.00 & 8.00 & 7.56 & 98.65 \\
9 & 10.20 & 36.17 & 8.00 & 8.36 & 98.52 \\
10 & 10.44 & 32.00 & 8.00 & 7.55 & 98.36 \\
\hline
\end{tabular}

value. This was very advantageous for the $3 \mathrm{D}$ printing system, because it meant that the printing parameters could be set according to the optimized model to ensure printing of the high-resolution scaffolds under high system stiffness.

The purpose of optimizing the printing process was to determine the microstructure of the bioactive porous scaffolds, thereby making it beneficial for improved in vivo nutrient diffusions, the removal of waste products, and more efficient vascularization as well as the preparation of the PEEK/HA composites. Figure 2 depicts the influence of individual control factors and their interactions on extrusion pressure based on the regression model after optimization.

3.3. SEM and CT Analyses for HA Scaffolds and PEEK/ HA Composites. Bioactive porous HA scaffolds with different filaments and pore sizes were printed following the optimization of the printing parameters. The microscopic morphologies of a sintered HA scaffold analyzed using SEM technology are presented in Figure 3a,b. The scaffolds exhibited a uniform microstructure following the optimization of the extrusion process. The minimum diameter of the HA filament reached $30 \mu \mathrm{m}$, which was the highest resolution the bioceramic scaffold ever reported.

Figure 3c,d presents a 3D image of a PEEK/HA composite constructed using CT technology. The PEEK/HA composite 

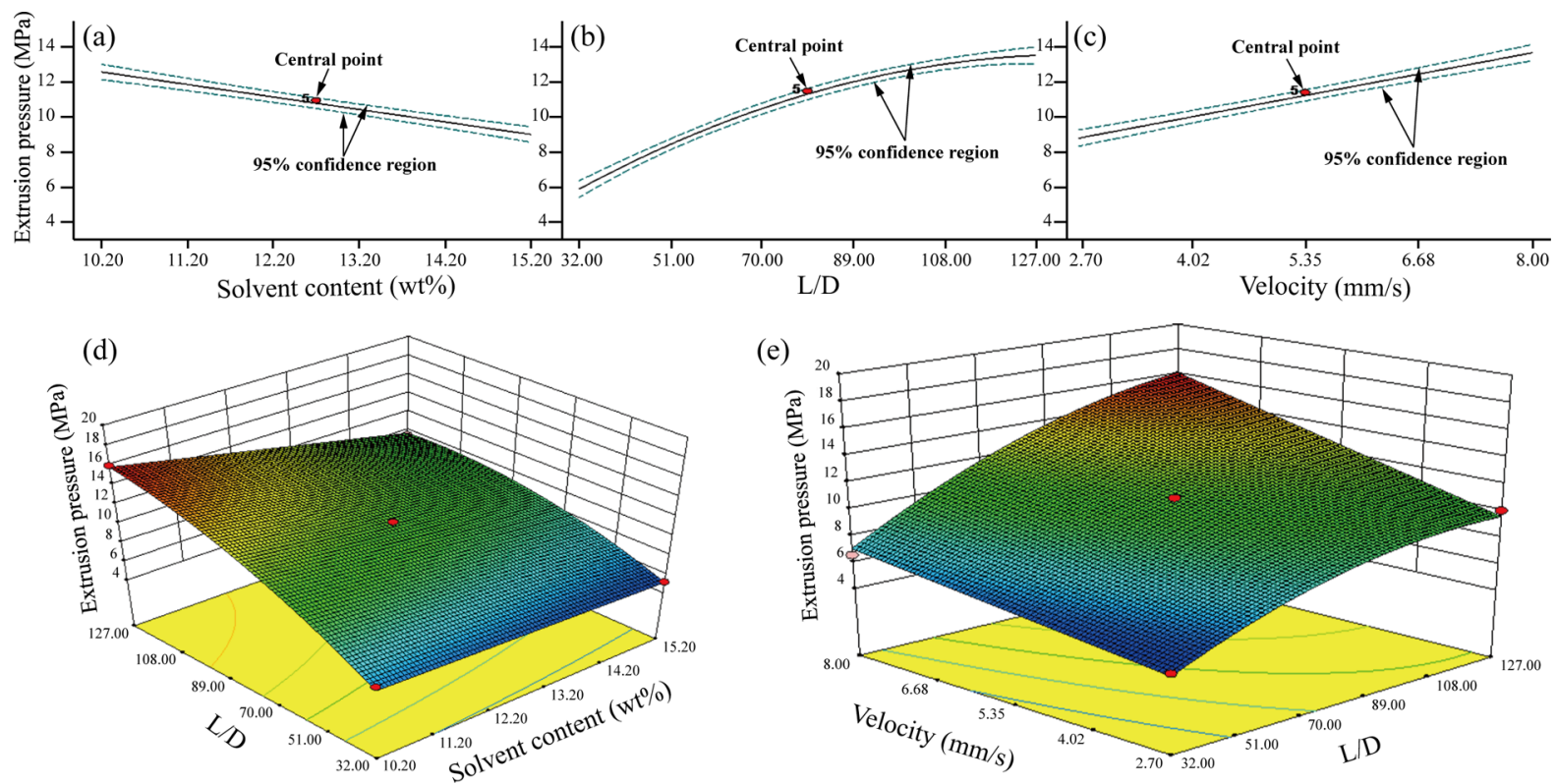

(e)

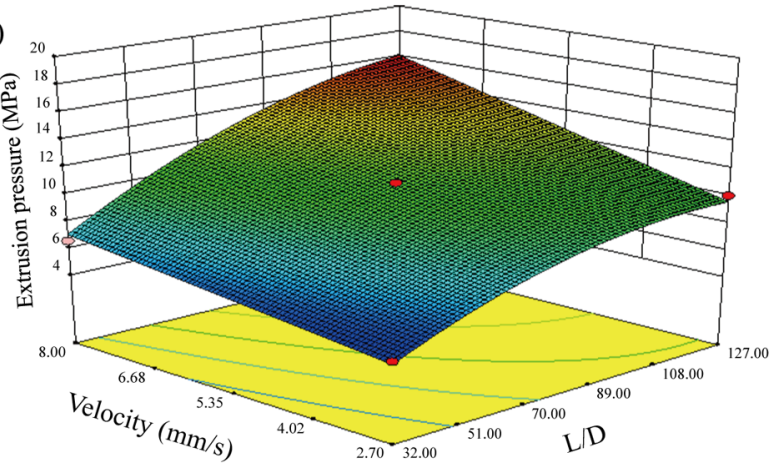

Figure 2. Influence of individual control factors and their interactions on extrusion pressure based on the regression model after optimization: (a) factor $A$, (b) factor $B$, (c) factor $C$, (d) interaction of $A B$, and (e) interaction of $B C$.

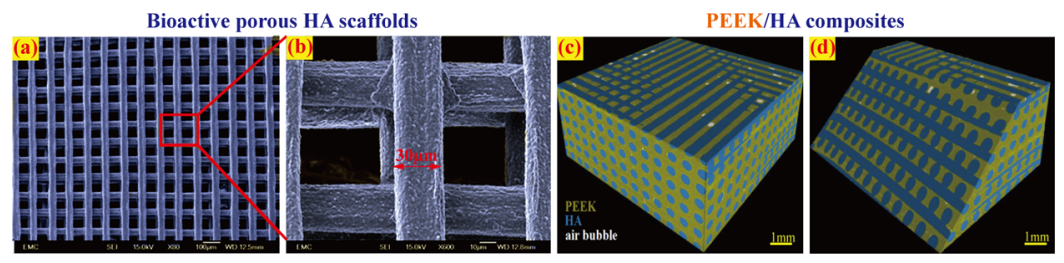

Figure 3. Microscopic morphology of the typical HA and PEEK/HA composites: (a,b) SEM image of a sintered HA scaffold with $\sim 30 \mu \mathrm{m}$ filaments and (c,d) CT image of a PEEK/HA composite.

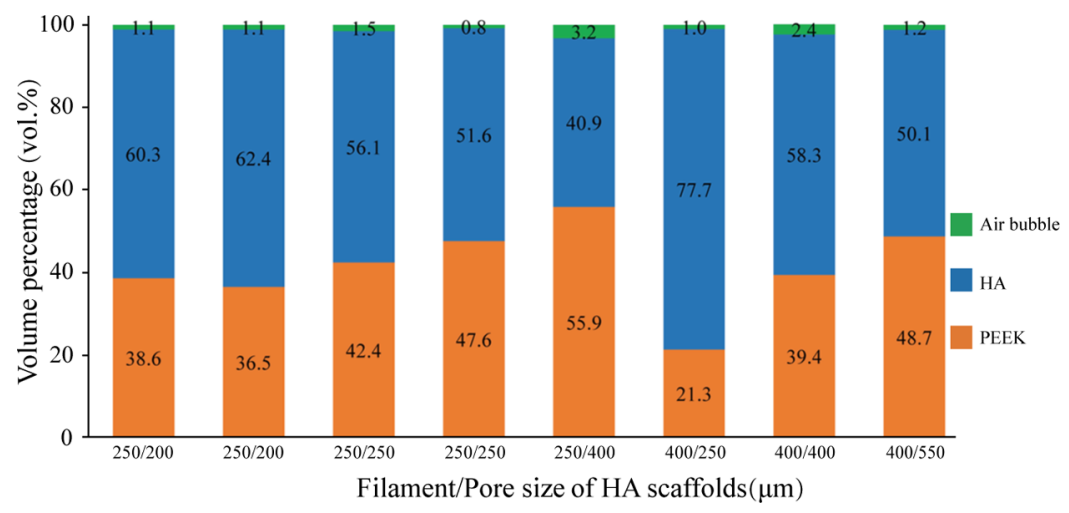

Figure 4. CT analysis results of volume percentage of PEEK/HA samples prepared by static loading.

was produced successfully through optimized compression molding using static loading with the optimal molding temperature and pressure of $400{ }^{\circ} \mathrm{C}$ and $0.39 \mathrm{MPa}$, respectively. HA scaffolds were fully infiltrated by PEEK with an infiltration depth of $3 \mathrm{~mm}$, while maintaining the $\mathrm{HA}$ network structure and uniformity, which meant that there was a good interface between the HA filaments and the PEEK matrix. Figure 4 depicts the $\mathrm{CT}$ analysis results of the volume percentages of PEEK/HA samples prepared using static loading.

The above analysis results verify the effectiveness of the method proposed in this study for the preparation of PEEK/
HA composites to accurately control the microstructure and generate a very consistent and repeatable overall process.

\section{BIOLOGICAL AND MECHANICAL PERFORMANCE VERIFICATIONS}

4.1. Cell Viability Both in HA Scaffolds and PEEK/HA Composites. The in vitro cell viability and biocompatibility test of the HA scaffolds and PEEK/HA samples were carried out for the assessment of the biological performance. Figure $5 \mathrm{a}-\mathrm{c}$ illustrates the cell viability of the HA scaffold; in the figure, the red spots indicate dead cells, the green areas indicate that the cells are alive and delineate the boundary of each cell, and the blue stains indicate the nuclei of the cells. Excellent cell 

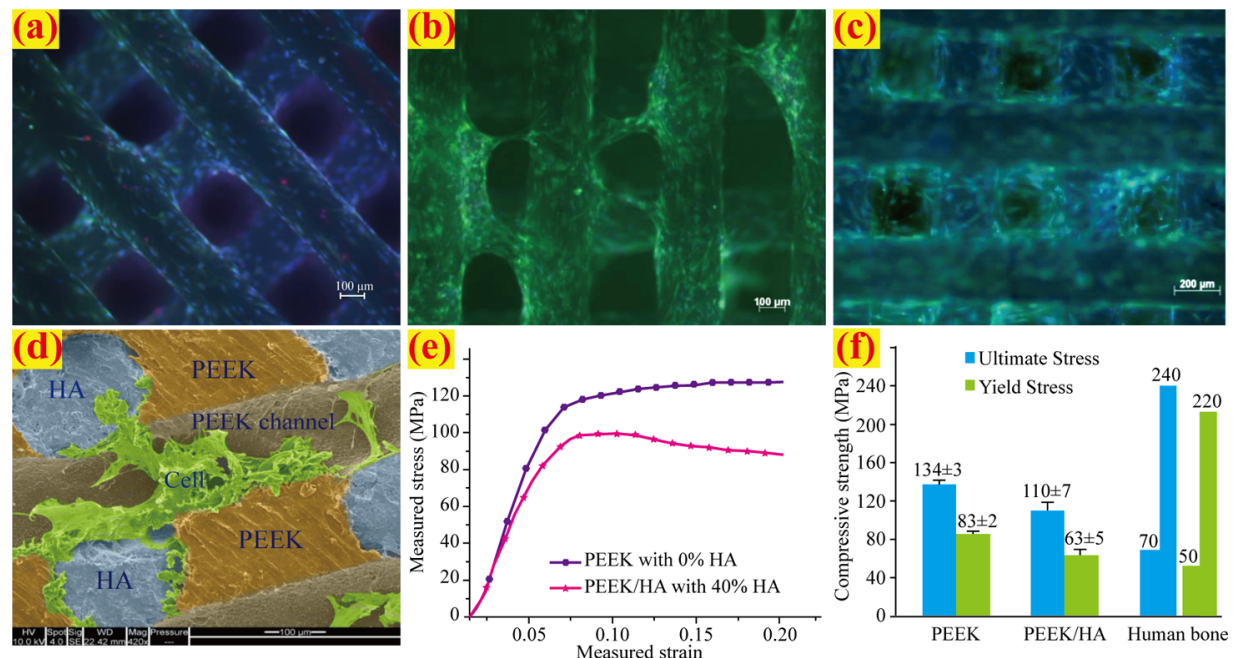

Figure 5. Biological and mechanical performance verifications: (a) cultured cells in HA scaffold within 1 day, (b) cultured cells in HA scaffold after 1 day, (c) cultured cells in HA scaffold at 7 days, (d) SEM imaging of the cell surface interaction and adhesion at PEEK/HA composite after 7 days, (e) measured stress-strain curve, and (f) comparison of compressive strength.

adhesion and viability were observed by a cell tracker green/ ethidium homodimer staining within 1 day, as shown in Figure 5a. The cells tended to row/bridge from one portion of a filament to the adjacent filament after just 1 day, as presented in Figure 5b. Widespread cell growth, proliferation, and pores filling were observed at 7 days, as displayed in Figure 5c. SEM imaging in Figure 5d revealed cell surface interaction and adhesion among the HA surface, the PEEK/HA boundary, and the interface of PEEK surface roughness variations. The results of biological tests confirmed excellent biocompatibility.

\subsection{Compression Test of the PEEK/HA Composites.} PEEK/HA composites with mechanical strength that is too strong or too weak are inappropriate for load-bearing bone applications. To verify the mechanical properties of the composites prepared in this study method, the parameters of the PEEK/HA were designed based on the mechanical properties of the human cortical bone. HA scaffolds with filament sizes of $400 \mu \mathrm{m}$ and pore sizes of $700 \mu \mathrm{m}$ were 3D printed and overmolded with PEEK using the procedure described in this study. The produced PEEK/HA samples were cut at sizes of $6 \times 6 \times 6 \mathrm{~mm}^{3}$ using a diamond cutter and subjected to further $\mathrm{CT}$ analysis. The samples with average HA volume percentages of $40 \%$ were subjected to unconfined, uniaxial compression tests using an Instron 8032 test machine at strain rate of $3 \times 10^{-3} / \mathrm{s}$. A $100 \mathrm{kN}$ load cell was used, and the test data were collected using Instron's StrainSmart 6200 software. Six samples were tested for reproducibility. The unfilled PEEK samples with 0\% HA were also printed and tested as a control.

The mechanical testing results are presented in Figure 5e,f, where the data for human cortical bone were taken from ref 40 . As seen in Figure 5f, the PEEK/HA possessed yields and compressive strengths within the range of the human cortical bone, which is an advantage compared to metal biomaterials. The mismatched mechanical strength of metal biomaterials with bone can cause stress shielding. However, the biological and mechanical properties of PEEK/HA composites prepared in this study can be adjusted by controlling the filament and/or pore size of HA with a computer-controlled distribution for different load-bearing or non-loadbearing applications.

\section{CONCLUSIONS}

(1) A promising strategy was developed for the preparation of bioactive PEEK/HA composites with the aim of controlling the biological and mechanical properties of different parts of the composites. The strategy integrated SEF 3D printing technology to print high-resolution HA scaffolds and compression molding processes for the production of bioactive PEEK/HA composites.

(2) An optimized model established using RSM was employed to optimize the extrusion process parameters. The experimental results indicated that the extrusion pressure after optimization was much lower than the target value, which meant that the printing parameters could be set according to the optimized model under high system stiffness. The optimization method in this study for bone scaffolds has not been reported.

(3) The SEM and CT analysis results indicated that the bioactive PEEK/HA composites exhibited a uniform microstructure and a good interface between the HA filaments and the PEEK matrix following the optimization of the process parameters. This verifies the effectiveness of the method proposed in this study in accurately controlling the microstructure and generating a very consistent and repeatable overall process.

(4) The biological and mechanical performance test results confirmed that the PEEK/HA composites possessed excellent biocompatibility as well as yields and compressive strengths, within the range of the human cortical bone, suitable for load-bearing applications, which validated the ability of the strategy to accurately control the properties of bioactive PEEK/HA composites.

\section{ASSOCIATED CONTENT}

\section{(S Supporting Information}

The Supporting Information is available free of charge on the ACS Publications website at DOI: 10.1021/acsomega.9b02572. 
Detailed fabricating method of this study and RSM experiment results of the two models compared with the measured values $(\mathrm{PDF})$

\section{AUTHOR INFORMATION}

\section{Corresponding Authors}

*E-mail: gyzhong@njau.edu.cn (G.Z.).

*E-mail: S.Yang@soton.ac.uk (S.Y.).

\section{ORCID $\odot$}

Gaoyan Zhong: 0000-0002-5079-4721

\section{Author Contributions}

${ }^{\#}$ G.Z. and M.V. contributed equally to this work.

\section{Notes}

The authors declare no competing financial interest.

\section{ACKNOWLEDGMENTS}

The authors are grateful to the Faculty of Engineering and the Environments, University of Southampton and Invibio Ltd. for their support. The authors are also grateful to the Bone and Joint Research Group, Centre for Human Development, Stem Cells and Regeneration, Faculty of Medicine, University of Southampton for their help with in vitro analysis. This study was also supported by State Key Laboratory of Materials Processing and Die \& Mould Technology, Huazhong University of Science and Technology of China (no. P2020002) and The introduction projects of high-end foreign experts in 2019 for strategic science and technology development, Ministry of Science and Technology of the People's Republic of China (no. G20190010113).

\section{REFERENCES}

(1) For a strong demand for bone injury repair and PEEK performance, see:Vaezi, M. 3D printing of Bone Tissue Engineering Scaffolds and Production of PEEK-based Biocomposites; University of Southampton: UK, 2017.

(2) Najeeb, S.; Zafar, M. S.; Khurshid, Z.; Siddiqui, F. Applications of polyetheretherketone (PEEK) in oral implantology and prosthodontics. J. Prosthodont. Res. 2016, 60, 12-19.

(3) Torstrick, F. B.; Lin, A. S. P.; Potter, D.; Safranski, D. L.; Sulchek, T. A.; Gall, K.; Guldberg, R. E. Porous PEEK improves the bone-implant interface compared to plasma-sprayed titanium coating on PEEK. Biomaterials 2018, 185, 106-116.

(4) Wenz, L. M.; Merritt, K.; Brown, S. A.; Moet, A.; Steffee, A. D. In vitro biocompatibility of polyetheretherketone and polysulfone composites. J. Biomed. Mater. Res. 1990, 24, 207-215.

(5) Petillo, O.; Peluso, G.; Ambrosio, L.; Nicolais, L.; Kao, W. J.; Anderson, J. M. In vivo induction of macrophage Ia antigen (MHC class II) expression by biomedical polymers in the cage implant system. J. Biomed. Mater. Res. 1994, 28, 635-646.

(6) Hunter, A.; Archer, C. W.; Walker, P. S.; Blunn, G. W. Attachment and proliferation of osteoblasts and fibroblasts on biomaterials for orthopaedic use. Biomaterials 1995, 16, 287-295.

(7) Katzer, A.; Marquardt, H.; Westendorf, J.; Wening, J. V.; von Foerster, G. Polyetheretherketone-cytotoxicity and mutagenicity in vitro. Biomaterials 2002, 23, 1749-1759.

(8) Pimentel, C. A.; de Lima Souza, J. W.; dos Santos, F. S. F.; de Sá, M. D.; Ferreira, V. P.; de Carvaiho Barreto, G. B.; Bacalhau Rodrigues, J. F.; Bacalhau de Sousa, W. J.; Britto Filho, C. O.; Alves de Sousa, F. K.; Lia Fook, M. V. Sulfonated poly(ether ether ketone)/ hydroxyapatite membrane as biomaterials: process evaluation. Polim.: Cienc. Tecnol. 2019, 29, e2019009. . For three main strategies to improve the osseointegration of PEEK-based implants, see:

(9) Ma, R.; Tang, T. Current Strategies to Improve the Bioactivity of PEEK. Int. J. Mol. Sci. 2014, 15, 5426-5445.
(10) Li, X.; He, J.; Bian, W.; Li, Z.; Zhang, W.; Li, D.; Snedeker, J. G. A novel silk-based artificial ligament and tricalcium phosphate/ polyether ether ketone anchor for anterior cruciate ligament reconstruction - Safety and efficacy in a porcine model. Acta Biomater. 2014, 10, 3696-3704.

(11) Wu, X.; Liu, X.; Wei, J.; Ma, J.; Deng, F.; Wei, S. Nano-TiO2/ PEEK bioactive composite as a bone substitute material: in vitro and in vivo studies. Int. J. Nanomed. 2012, 7, 1215-1225.

(12) Han, C.-M.; Lee, E.-J.; Kim, H.-E.; Koh, Y.-H.; Kim, K. N.; Ha, Y.; Kuh, S.-U. The electron beam deposition of titanium on polyetheretherketone (PEEK) and the resulting enhanced biological properties. Biomaterials 2010, 31, 3465-3470.

(13) Lee, J. H.; Jang, H. L.; Lee, K. M.; Baek, H.-R.; Jin, K.; Hong, K. S.; Noh, J. H.; Lee, H.-K. In vitro and in vivo evaluation of the bioactivity of hydroxyapatite-coated polyetheretherketone biocomposites created by cold spray technology. Acta Biomater. 2013, 9, 61776187.

(14) Wang, L.; He, S.; Wu, X.; Liang, S.; Mu, Z.; Wei, J.; Deng, F.; Deng, Y.; Wei, S. Polyetheretherketone/nano-fluorohydroxyapatite composite with antimicrobial activity and osseointegration properties. Biomaterials 2014, 35, 6758-6775.

(15) Zhao, Y.; Wong, H. M.; Wang, W.; Li, P.; Xu, Z.; Chong, E. Y. W.; Yan, C. H.; Yeung, K. W. K.; Chu, P. K. Cytocompatibility, osseointegration, and bioactivity of three-dimensional porous and nanostructured network on polyetheretherketone. Biomaterials 2013, 34, 9264-9277. . For manufacturing methods to produce PEEK/HA composites, see:

(16) Tan, K. H.; Chua, C. K.; Leong, K. F.; Naing, M. W.; Cheah, C. $\mathrm{M}$. Fabrication and characterization of three-dimensional poly(etherether-ketone)/-hydroxyapatite biocomposite scaffolds using laser sintering. Proc. Inst. Mech. Eng., Part H 2005, 219, 183-194.

(17) Rashidi, A. R.; Mat, U. W.; Abdullah, R. A. Effect of a Coupling Agent On Mechanical and Biological Properties of Polyetheretherketone/Hydroxyapatite Bioactive Composite for Prosthetic Medical Device. Compos. Sci. Technol. 2011, 471-472, 898.

(18) Ma, R.; Fang, L.; Luo, Z.; Weng, L.; Song, S.; Zheng, R.; Sun, $\mathrm{H}$.; $\mathrm{Fu}, \mathrm{H}$. Mechanical performance and in vivo bioactivity of functionally graded PEEK-HA biocomposite materials. J. Sol-Gel Sci. Technol. 2014, 70, 339-345.

(19) Evans, N. T.; Torstrick, F. B.; Lee, C. S. D.; Dupont, K. M.; Safranski, D. L.; Chang, W. A.; Macedo, A. E.; Lin, A. S. P.; Boothby, J. M.; Whittingslow, D. C.; Carson, R. A.; Guldberg, R. E.; Gall, K. High-strength, surface-porous polyether-ether-ketone for load-bearing orthopedic implants. Acta Biomater. 2015, 13, 159-167.

(20) Yuan, B.; Cheng, Q.; Zhao, R.; Zhu, X.; Yang, X.; Yang, X.; Zhang, K.; Song, Y.; Zhang, X. Comparison of osteointegration property between PEKK and PEEK: Effects of surface structure and chemistry. Biomaterials 2018, 170, 116-126.

(21) Yuan, B.; Chen, Y.; Lin, H.; Song, Y.; Yang, X.; Tang, H.; Xie, E.; Hsu, T.; Yang, X.; Zhu, X.; Zhang, K.; Zhang, X. Processing and Properties of Bioactive Surface-Porous PEKK. ACS Biomater. Sci. Eng. 2016, 2, 977-986.

(22) Vaezi, M.; Black, C.; Gibbs, D. M. R.; Oreffo, R. O. C.; Brady, M.; Moshrefi-Torbati, M.; Yang, S. Characterization of New PEEK/ HA Composites with 3D HA Network Fabricated by Extrusion Freeforming. Molecules 2016, 21, 687.

(23) Vaezi, M.; Yang, S. A novel bioactive PEEK/HA composite with controlled 3D interconnected HA network. Int. J. Bioprint. 2015, $1,66-76$

(24) Vaezi, M.; Yang, S. Extrusion-based additive manufacturing of PEEK for biomedical applications. Virtual Phys. Prototyp. 2015, 10, 123-135.

(25) Vaezi, M.; Zhong, G.; Kalami, H.; Yang, S. Extrusion-based 3D printing technologies for 3D scaffold engineering. In Functional 3D Tissue Engineering Scaffolds; Deng, Y., Kuiper, J., Eds.; Academic Press, Woodhead Publishing, 2018; pp 235-254.

(26) Zhong, G.; Vaezi, M.; Liu, P.; Pan, L.; Yang, S. Characterization approach on the extrusion process of bioceramics for the $3 \mathrm{D}$ printing 
of bone tissue engineering scaffolds. Ceram. Int. 2017, 43, 1386013868. . For response surface methodology, see:

(27) Bezerra, M. A.; Santelli, R. E.; Oliveira, E. P.; Villar, L. S.; Escaleira, L. A. Response surface methodology (RSM) as a tool for optimization in analytical chemistry. Talanta 2008, 76, 965-977.

(28) Chen, S.; Zeng, Z.; Hu, N.; Bai, B.; Wang, H.; Suo, Y. Simultaneous optimization of the ultrasound-assisted extraction for phenolic compounds content and antioxidant activity of Lycium ruthenicum Murr. fruit using response surface methodology. Food Chem. 2018, 242, 1-8.

(29) Celik, F.; Aslani, M. A. A.; Can, S. S. Study of the Bioaccumulation of UO22+ onto the Green Microalgae Botryococcus braunii Using Response Surface Methodology. Turk. J. Fish. Aquat. Sci. 2019, 19, 593-604.

(30) Monforte, A. R.; Oliveira, C.; Martins, S. I. F. S.; Silva Ferreira, A. C. Response surface methodology: A tool to minimize aldehydes formation and oxygen consumption in wine model system. Food Chem. 2019, 283, 559-565.

(31) Coelho, T. L. S.; Braga, F. M. S.; Silva, N. M. C.; Dantas, C.; Lopes Júnior, C. A.; de Sousa, S. A. A.; Vieira, E. C. Optimization of the protein extraction method of goat meat using factorial design and response surface methodology. Food Chem. 2019, 281, 63-70.

(32) Diañez, I.; Gallegos, C.; Brito-de la Fuente, E.; Martínez, I.; Valencia, C.; Sánchez, M. C.; Diaz, M. J.; Franco, J. M. 3D printing in situ gelification of $\kappa$-carrageenan solutions: Effect of printing variables on the rheological response. Food Hydrocolloids 2019, 87, 321-330.

(33) Soni, A.; Kumar, S.; Singh, B. Prediction of tensile strength of 3D printed part using response surface methodology. J. Braz. Soc.

Mech. Sci. Eng. 2018, 40, 566. . For microstructure analysis using SEM and CT techniques, see:

(34) Williams, J. M.; Adewunmi, A.; Schek, R. M.; Flanagan, C. L.; Krebsbach, P. H.; Feinberg, S. E.; Hollister, S. J.; Das, S. Bone tissue engineering using polycaprolactone scaffolds fabricated via selective laser sintering. Biomaterials 2005, 26, 4817-4827.

(35) Edri, E.; Kirmayer, S.; Mukhopadhyay, S.; Gartsman, K.; Hodes, G.; Cahen, D. Elucidating the charge carrier separation and working mechanism of $\mathrm{CH} 3 \mathrm{NH} 3 \mathrm{PbI} 3$-xClx perovskite solar cells. Nat. Commun. 2014, 5, 3461.

(36) Li, T.; Heenan, T. M. M.; Rabuni, M. F.; Wang, B.; Farandos, N. M.; Kelsall, G. H.; Matras, D.; Tang, C.; Lu, X.; Jacques, S. D. M.; Brett, D. J. L.; Shearing, P. R.; Di Michiel, M.; Beale, A. M.; Vamvakeros, A.; Li, K. Design of next-generation ceramic fuel cells and real-time characterization with synchrotron X-ray diffraction computed tomography. Nat. Commun. 2019, 10, 1497.

(37) Sartori-Rupp, A.; Cervantes, D. C.; Pepe, A.; Gousset, K.; Delage, E.; Corroyer-Dulmont, S.; Schmitt, C.; Krijnse-Locker, J.; Zurzolo, C. Correlative cryo-electron microscopy reveals the structure of TNTs in neuronal cells. Nat. Commun. 2019, 10, 342.

(38) Barui, S.; Panda, A. K.; Naskar, S.; Kuppuraj, R.; Basu, S.; Basu, B. 3D inkjet printing of biomaterials with strength reliability and cytocompatibility: Quantitative process strategy for Ti-6Al-4V. Biomaterials 2019, 213, 119212.

(39) Lai, Y.; Li, Y.; Cao, H.; Long, J.; Wang, X.; Li, L.; Li, C.; Jia, Q.; Teng, B.; Tang, T.; Peng, J.; Eglin, D.; Alini, M.; Grijpma, D. W.; Richards, G.; Qin, L. Osteogenic magnesium incorporated into PLGA/TCP porous scaffold by $3 \mathrm{D}$ printing for repairing challenging bone defect. Biomaterials 2019, 197, 207-219. . About the data for human cortical bone, see:

(40) Oehman, C.; Baleani, M.; Pani, C.; Taddei, F.; Alberghini, M.; Viceconti, M.; Manfrini, M. Compressive behaviour of child and adult cortical bone. Bone 2011, 49, 769-776. 